\title{
BIO-BASED EPOXY RESINS AND COMPOSITES FROM EPOXIDIZED LINSEED OIL CROSSLINKED WITH DIFFERENT CYCLIC ANHYDRIDES AND THEIR COMBINATION WITH LIGNIN
}

\author{
ROXANA DINU and ALICE MIJA \\ Université Côte d'Azur, Institut de Chimie de Nice, UMR CNRS 7272, \\ 28 Av. Valrose, 06108 Nice Cedex 02, France \\ Corresponding author: Alice Mija, Alice.Mija@univ-cotedazur.fr
}

Dedicated to Academician Cristofor I. Simionescu, on his $100^{\text {th }}$ birth anniversary

\begin{abstract}
Biobased resins and composites with high biobased carbon content were prepared and characterized. Epoxidized linseed oil (ELO) was copolymerized with four cyclic anhydrides, the initiation step being optimized in terms of initiator nature and its ratio. The optimized ELO/anhydride formulations were combined with a high load of lignin, as biofiller, $~ 30 \mathrm{wt} \%$. The obtained materials were characterized by TGA, DSC, DMA, gel content, water absorption (WA) and Shore hardness tests. The results revealed very good thermomechanical properties, high gel content and low WA, opening the way to their utilization as a sustainable alternative to oil-based resins and composites.
\end{abstract}

\section{INTRODUCTION}

Plastics have become one of the most representative inventions in the evolution of the society, but their inadequate management has led to its conversion into a harmful and unfriendly factor for the environment. The first knowledge about the development and use of polymeric materials dates back to 1600 $\mathrm{BC},{ }^{1}$ but their industrial production and use began in 1950, generating so far around 6.3 billion tons of plastic worldwide. ${ }^{2}$ Both the continuous growth of the population and its needs, and the global pollution have led to an increased focus on the application and implementation of a sustainable economy. ${ }^{3}$ For this purpose, intense researches are carried out for the replacement of fossil derivatives, which are a limited resource and environmentally unfriendly, with natural and renewable ones. Also, a continuous challenge in research is to find effective ways of converting bioresources into fuels and chemicals, and to design new innovative, green and environmentally friendly routes of developing, recovering and reusing polymeric materials.
Epoxy resins are some of the most important thermoset materials due to their excellent bonding property, high mechanical properties, and chemical resistance. In addition, epoxy resins can have different properties, because they can be combined and cured with various compounds, leading to their use in a wide range of fields, such as composites, adhesives, coatings, civil engineering, automotive sector and electrical materials. $^{4-6}$ Most of the industrially used epoxy monomers are obtained from petroleum-based resources, but in the last decades, alternative molecules have been produced and studied, as for example, those derived from vegetable oils. Generally, vegetable oils are renewable materials constituted by triglycerides formed from glycerol and fatty acids. The epoxidation of vegetable oils, such as soybean oil or linseed oil, is a most important and useful exploitation of double bonds functionalization, leading to the generation of bio-based monomers and resins able to replace those from fossil 
derivatives, such as the diglycidyl ether of bisphenol A (DGEBA). ${ }^{7}$

Epoxidized linseed oil (ELO) is one of the compounds intensely investigated for the development of new resins and polymeric composites, due to its relatively high functional oxirane content. ${ }^{8}$ For example, Boquillon et al. ${ }^{9}$ developed thermoset polymeric networks based on ELO and dianhydride based curing agents. The influence of the dianhydride nature, but also of different types of catalysts, such as tertiary amines and imidazoles, on the curing mechanisms, the structure and the thermomechanical properties of the networks were investigated. Samper et al. ${ }^{10}$ developed new polymeric resins feasible to use in the development of green composites. The polymeric materials were designed from epoxidized soybean oil (ESO), epoxidized linseed oil (ELO) and different mixtures of the two monomers, crosslinked with phthalic anhydride and maleic anhydride, using benzyl dimethyl amine as catalyst. Based on the physico-chemical and mechanical investigations, the optimal formulations were found to be those with ELO and with 80:20 ELO:ESO. Important studies have also been carried out by Di Mauro et al. ${ }^{11-13}$ for a large series of epoxidized vegetable oils for the development of new polymeric resins with the capacity to be reprocessed and recycled, but also with physico-chemical and mechanical performances feasible for industrial use.

The most important renewable resource suitable for the development of new biopolymers and capable of replacing synthetic and petroleum-derived materials is biomass. ${ }^{14-16}$ Lignocellulosic biomass consists of three important carbohydrates, such as cellulose $(35-50 \%)$, hemicelluloses $(20-35 \%)$ and lignin $(10-25 \%) .{ }^{17}$ Lignin is a threedimensional amorphous phenolic polymer, whose structure is formed by three phenylpropanes building blocks, such as $p$ coumaryl alcohol, coniferyl alcohol, and sinapyl alcohol, connected through carboncarbon and ether bonds. ${ }^{18}$ Its function as cellular glue provides overall rigidity to the structure of plants and trees and resistance against insects and pathogens. Generally, softwoods contain more lignin than the hardwoods. ${ }^{19}$ Lignin is still a by-product of chemical pulping processes, and its characteristic functional chemical groups are hydroxyl (phenolic and alcoholic), methoxy, carbonyl and carboxyl. ${ }^{20,21}$ The annual lignin production is about 20 million tons worldwide, most of which is actually burned for energy. ${ }^{15,22}$ In an attempt to valorise it for the development of new materials based on natural raw products, lignin has been used with various polymers, such as polypropylene, ${ }^{23,24}$ poly(lactic acid) ${ }^{25,26}$ polyvinyl chloride, ${ }^{27}$ or different epoxies. ${ }^{28-31}$ In our previous studies, lignin was used as filler in the development of composites, using bio-resins based on resorcinol diglycidyl ether, ${ }^{32}$ or industrial by-products (humins from biorefineries) as polymeric matrices. ${ }^{33}$

The purpose of this work was the development of bio-based resins and composites using renewable, cost competitive and commercial compounds. Firstly, thermoset resins were developed based on epoxidized linseed oil crosslinked with four different anhydrides, the mixtures being initiated by 1-methylimidazole. Secondly, biobased composites were produced using a very large amount of kraft lignin, about $30 \%$ by weight. As far as we know, ELO-based epoxy resins have so far not been combined and reinforced with lignin. The curing behaviour of the resins, but also the influence of lignin on the crosslinking reactivity was investigated by differential scanning calorimetry (DSC). The physical, thermal, and thermo-mechanical properties of the designed resins and composites were studied using different technics, such as TGA and DMA, as well as Shore D hardness, water absorption and gel content assessment, for their subsequent classification in an industrial application area.

\section{EXPERIMENTAL}

\section{Materials}

The epoxy materials were developed starting from a commercially available epoxidized linseed oil (ELO), supplied by Valtris Specialty Chemicals. This bio-based epoxy is a yellow viscous liquid ( 1200 Pa.s), with an average molecular weight of about $980 \mathrm{~g} \cdot \mathrm{mol}^{-1}$ and an average functionality of 5.5 epoxides per triglyceride. Different anhydrides, such as cis1,2,3,6-tetrahydrophthalic anhydride (T; 95\%), hexahydro-4-methylphthalic anhydride $(\mathrm{H}$; mixture of cis and trans, 96\%), (2-dodecen-1-yl)succinic anhydride (D; 95\%), methyl nadic anhydride (M; $\geq$ $95.0 \%)$, were used as hardener, and 1- 
methylimidazole (1-MIM; $\geq 99 \%)$ as initiator. These chemical products were purchased from Sigma-Aldrich (France) and used as received, without further purification. The fractionated Kraft lignin (Lig), supplied by VTT Technical Research Centre (Finland), was used as structural reinforcing agent. This natural compound is a brown powder with a sulphur content of about $1-3 \%$ and a $\mathrm{pH}$ ranging between 2.5-7. The molecular representations of the compounds used in the manufacturing process of the epoxy materials are exhibited in Figure 1.

\section{Synthesis of crosslinked networks}

To design the epoxy resins, the 1:1 stoichiometric ratio of the epoxy groups to the anhydride groups was used. The proper amount of ELO was heated at $70{ }^{\circ} \mathrm{C}$ to decrease its viscosity. Then, the required amount of anhydride was added to the epoxy compound, and the mixtures were vigorously mechanically stirred homogeneously for $10 \mathrm{~min}$. To facilitate the reactions, 1methylimidazole (1-MIM) was used as initiator, being added in the proportion of $3 \mathrm{wt} \%$, based on the total weight of the curing agent-epoxy mixture. The homogenous blends were poured in silicon molds and introduced into a preheated convection oven for the curing and post-curing treatment.

The composite materials were developed by mechanically mixing the epoxy/anhydride stoichiometric blends with $30 \mathrm{wt} \%$ of kraft lignin, and after homogenization, $3 \mathrm{wt} \%$ initiator was added. To establish the optimum amount of filler, different percentages of lignin were tested by DSC, the crosslinking exothermic curves being displayed in Figure 2b. For complete curing of the resins and composites, the formulations were subjected to a two-stage curing process selected according to preliminary calorimetric DSC studies: $150{ }^{\circ} \mathrm{C}$ for 2 hours and then $180^{\circ} \mathrm{C}$ for 1.5 hours.

\section{Differential scanning calorimetry (DSC)}

The crosslinking profile of the epoxy-based resins, but also the influence of the lignin on the curing reactivity, was examined using a DSC 3 Mettler Toledo apparatus. Approximately 5-10 mg of fresh samples were placed in $40 \mu \mathrm{L}$ aluminium pans and scanned from 25 to $250{ }^{\circ} \mathrm{C}$ at a heating rate of 10 ${ }^{\circ} \mathrm{C} \cdot \mathrm{min}^{-1}$. The onset $\left(T_{\text {onset }}\right)$ and end curing $\left(T_{\text {end }}\right)$ temperatures, the temperature at which the maximum crosslinking reaction takes place $\left(T_{\text {peak }}\right)$, and the reaction enthalpy $(\Delta H)$ of the ELO-based resins and composite formulations were determined. The DSC technique was also used to investigate the glass transition, $T_{\mathrm{g}}$, of the materials. Crosslinked samples of $12-17 \mathrm{mg}$ were placed in $40 \mu \mathrm{L}$ aluminium crucibles and subjected to a two heating-cooling cycle from -50 ${ }^{\circ} \mathrm{C}$ to $200{ }^{\circ} \mathrm{C} 10{ }^{\circ} \mathrm{C} \cdot \mathrm{min}^{-1}$. The $T_{\mathrm{g}}$ values were recorded from the second cycle and defined as the temperature at the inflection point in the plot of heat flow vs. temperature DSC curves. All the DSC data were analyzed by STARe Software.

\section{Thermogravimetric analysis (TGA)}

The thermal stabilities were examined using a TGA 2 Mettler Toledo device. Cured samples, of $15 \mathrm{mg}$, were placed into $70 \mu \mathrm{L}$ alumina crucibles and subjected to a heating program from 25 to $1000{ }^{\circ} \mathrm{C}$, at $10{ }^{\circ} \mathrm{C} \mathrm{min}^{-1}$, in an oxidative atmosphere $\left(50 \mathrm{~mL} \cdot \mathrm{min}^{-1}\right)$. The degradation temperature of the studied polymeric materials was recorded as the temperature at which the materials lose $5 \%$ of their mass $\left(T_{5 \%}\right)$.

\section{Dynamic mechanical analysis (DMA)}

The viscoelastic behavior of the resins and composites was studied using a DMA 1 Mettler Toledo. The specimens, with dimensions of about $50 \times 8 \times 4 \mathrm{~mm}^{3}$ (length $\times$ width $\times$ thickness), were analyzed from $-60{ }^{\circ} \mathrm{C}$ to $200{ }^{\circ} \mathrm{C}$, at a heating rate of $3{ }^{\circ} \mathrm{C} \cdot \mathrm{min}^{-1}$. The frequency and the amplitude were set at $1.0 \mathrm{~Hz}$ and $20 \mu \mathrm{m}$, respectively. The DMA experiments were performed using a threepoint bending accessory, and the obtained data, such as storage modulus ( $\left.E^{\prime}\right)$, loss modulus ( $\left.E^{\prime \prime}\right)$, and damping factor $\left(\tan \delta=E^{\prime} / E^{\prime \prime}\right)$, were examined by STARe Software. To reduce the errors, each specimen was analyzed twice, the results being averaged.

\section{Shore hardness tests}

The hardness tests were carried out using a Shore D durometer (Zwick Roell 3116 Hardness Tester), in compliance with the standards: ISO 7619-1, ASTM D2240, and ISO 868. The stiffness of the resins and composites was determined applying a load force of $50 \mathrm{~N} \pm 0.5 \mathrm{~N}$, the values being recorded upon firm contact between the device presser foot and the analyzed sample. For greater accuracy, a minimum of six measurements were taken and the average values were calculated.

\section{Water absorption}

The water absorbed (WA) by the epoxy-based resins and the composites was investigated using the ASTM D570 ${ }^{34}$ standard test method, the obtained results being compared with those obtained using the DSC method. Firstly, rectangular samples $\left(10 \times 8 \times 4 \mathrm{~mm}^{3}\right)$ were dried in an oven at $50{ }^{\circ} \mathrm{C}$ for $24 \mathrm{~h}$, cooled in a desiccator, and then weighed $\left(W_{0}\right)$ with a ML3002T Mettler Toledo precision balance. For the $24 \mathrm{~h}$ immersion procedure (ASTM D570 standard), the conditioned specimens were entirely immersed in distilled water at room temperature and maintained for $24 \mathrm{~h}$. At the end of the $24 \mathrm{~h}$, the tested samples were removed from the water, carefully wiped with filter paper and their mass was measured $\left(W_{t}\right)$. The moisture content ratio (WA, \%) was calculated using the equation: ${ }^{34}$ 
WA, $\%=\frac{W_{t}-W_{0}}{W_{0}} \times 100$

where $W_{0}$ represents the conditioned weight of the tested sample and $W_{\mathrm{t}}$ is the wet mass of the tested sample after $24 \mathrm{~h}$ of immersion.

The WA was also determined by DSC. Samples of $5 \mathrm{mg}$, collected from the specimens analyzed by the prior procedure, were placed into $40 \mu \mathrm{L}$ aluminium crucibles and subjected to a scan from
$30{ }^{\circ} \mathrm{C}$ to $300{ }^{\circ} \mathrm{C}$, at a heating rate of $10{ }^{\circ} \mathrm{C} \cdot \mathrm{min}^{-1}$. Subsequently, the samples were tempered to ambient temperature, followed by a similar second heating program. The moisture content by DSC was calculated using the water evaporation heat of $2400 \mathrm{~J} . \mathrm{g}^{-1}$, and the obtained values were compared with the data achieved by ASTM D570 standard method.

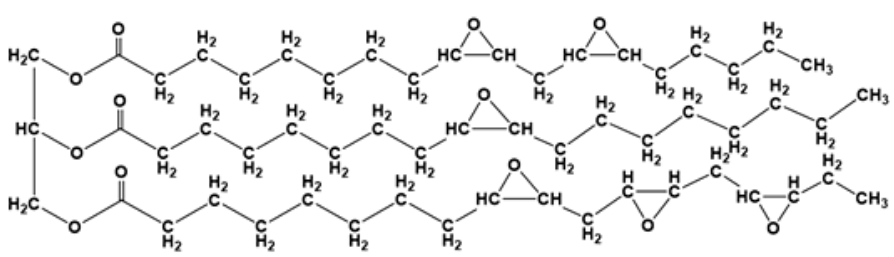

a) ELO

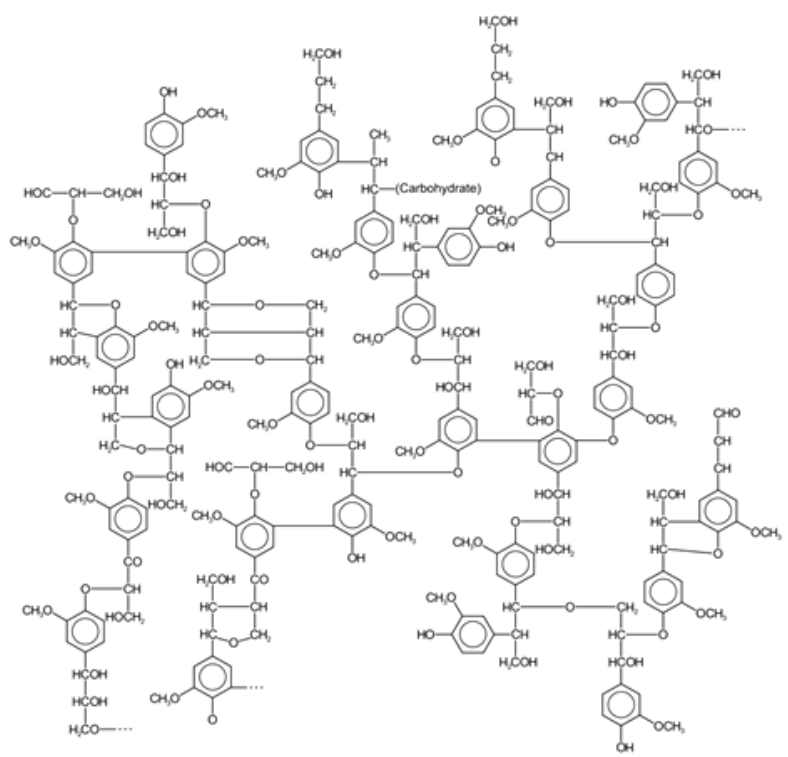

b) Lig

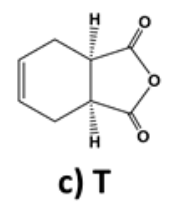<smiles>CC1CCC2C(CC(=O)C2O)C1</smiles>

d) $\mathbf{H}$<smiles>CC1CC2CC1C1C(C)OC(O)C2C1C</smiles>

e) $M$<smiles>CCCCCCCCCCCCCC1CC(O)CO1</smiles>

f) $D$

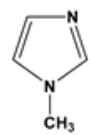

g) 1-MIM

Figure 1: Chemical structure of: a) epoxidized linseed oil (ELO), b) Kraft lignin (Lig), c) cis-1,2,3,6tetrahydrophthalic anhydride $(\mathrm{T})$, d) hexahydro-4-methylphthalic anhydride $(\mathrm{H})$, e) methyl nadic anhydride (M), f) (2-dodecen-1-yl)succinic anhydride (D) and g) 1-methylimidazole (1-MIM)

\section{Gel content}

The gel content (GC) of the materials was determined using the solvent extraction method. Samples with predetermined dimensions $(20 \times 8 \times$ $\left.4 \mathrm{~mm}^{3}\right)$ were initially weighed $\left(W_{0}\right)$ and then immersed in acetone solvent at room temperature. The tested formulations were kept in solvent for $24 \mathrm{~h}$, then removed and dried in the oven at $50{ }^{\circ} \mathrm{C}$ to a constant weight $\left(W_{\mathrm{d}}\right)$. The $\mathrm{GC}$ was calculated using the equation: ${ }^{35}$
$\mathbf{G C}, \%=100-\left[\frac{\left(\mathbf{W}_{0}-\mathbf{W}_{\mathrm{d}}\right) \times 100}{\mathbf{W}_{0}}\right]$

\section{RESULTS AND DISCUSSION Study of copolymerization reactivity by DSC}

The dynamic curing behavior of the ELO monomer with different anhydrides, as well as the influence of lignin on this curing, was studied by DSC. Firstly, different initiator 
types and concentrations were studied by DSC to find the best reactivity for the selected epoxy/anhydride systems (Fig. 2a). Based on the DSC results, $3 \mathrm{wt} \%$ of 1-MIM was selected as the optimal initiator and ratio due to the lowest maximum temperature and interval of reaction, and due to the high reaction enthalpy. Boquillon et al. ${ }^{9}$ studied the influence of different anhydrides and initiators on the physico-chemical and mechanical properties of the ELO polymeric networks. After the kinetic investigations, they concluded that imidazole was more effective than the tertiary amines in the initiation of the polymerization, because the resulting networks showed a higher conversion of anhydride.

To determine the optimal amount of lignin that can be included in the epoxy/anhydride formulations, mass percentages of $5,10,15$, 20, 30 and $40 \mathrm{wt} \%$ were tested. As an example, non-isothermal curing DSC curves of the $\mathrm{ELO} /(2-D o d e c e n-1-\mathrm{yl})$ succinic anhydride formulation with various lignin amounts are given in Figure 2b.

The curing reaction of ELO with (2dodecen-1-yl) succinic anhydride (D) appears as a single broad exothermic event, with an exothermal shoulder at $\sim 190{ }^{\circ} \mathrm{C}$, a sign of secondary reactions, such as epoxy homopolymerization, etherification, etc. From Figure $2 b$, it can be seen that, with the addition of lignin, the peak of this secondary reaction decreases, disappearing for mixtures with 30 and $40 \mathrm{wt} \%$ lignin. The enthalpy of

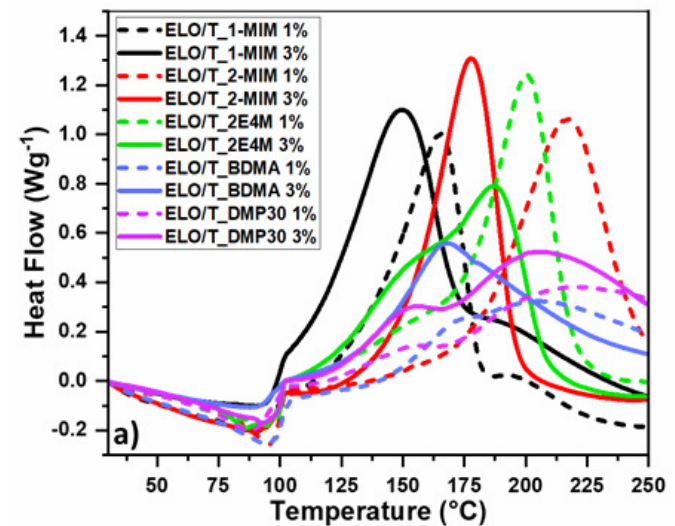

the epoxy/anhydride polymerization was determined by integrating the exothermic peak, while for the mixtures with lignin, the enthalpy values were normalized to the mass of the resin in the analyzed compositions. The influence of the Lig on the resins' reactivity can be observed from the modification of the $T_{\text {peak }}$, as well as of the reaction interval of temperature. As the percentage of lignin in the formulation increases, the $T_{\text {peak }}$ value shifts to a lower temperature, except for the mixtures with $5 \mathrm{wt} \%$ Lig.

Generally, the $T_{\text {peak }}$ temperature achieved from DSC curves is often taken as an indicator to assess the reactivity of the analyzed systems. According to previous studies, ${ }^{36,37}$ it is known that the lower is the maximum temperature of the reaction, the higher is the reactivity. By DSC analysis and by the manufacturing protocol, it was established that the optimal and maximum amount of lignin to be added to the epoxy/anhydride systems is $30 \mathrm{wt} \%$.

Figure 3 displays the DSC heating thermograms of ELO/anhydride curing systems with and without lignin, and the related data are summarized in Table 1. According to the obtained DSC data, the epoxy curing reactions of ELO/T, ELO/D and ELO/H exhibit similar $T_{\text {peak }}$ values of about 150-153 ${ }^{\circ} \mathrm{C}$, while the maximum temperature of reaction for the ELO/M is higher, being $\sim 178^{\circ} \mathrm{C}$.

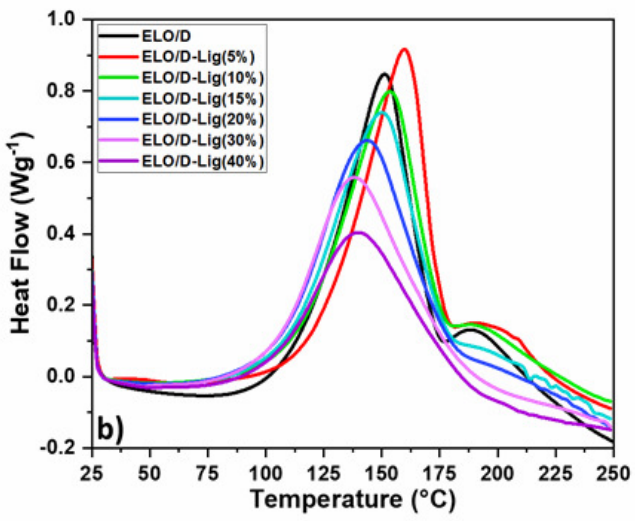

Figure 2: DSC curing during heating at $10{ }^{\circ} \mathrm{C} / \mathrm{min}$ of a) ELO/cis-1,2,3,6-tetrahydrophthalic anhydride formulation initiated by $1 \mathrm{wt} \%$ (dot line) or $3 \mathrm{wt} \%$ (line) 1-methylimidazole (1-MIM, black curves), 2methylimidazole (2-MIM, red curves), 2-ethyl-4-methylimidazole (2E4M, green curves), N,Ndimethylbenzylamine (BDMA, blue curves), 2,4,6-tris(dimethylaminomethyl)phenol (DMP30, purple curves), and b) ELO/ (2-dodecen-1-yl)succinic anhydride curing formulations with different percentages of lignin 


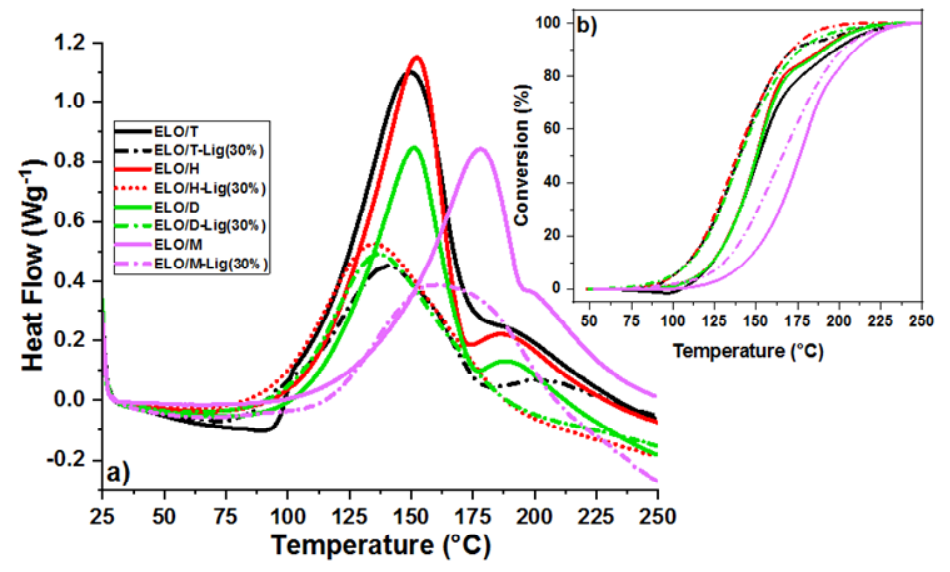

Figure 3: a) DSC curves of the curing process of the ELO/anhydride systems without and with $30 \mathrm{wt} \%$ lignin, and b) the conversion profile as a function of temperature

Table 1

DSC data of the curing process of ELO/anhydride formulations with and without $30 \mathrm{wt} \%$ lignin - reaction peak temperature, reaction interval of temperature and reaction enthalpy

\begin{tabular}{lcccccccc}
\hline & \multicolumn{2}{c}{ ELO/T } & \multicolumn{2}{c}{ ELO/H } & \multicolumn{2}{c}{ ELO/D } & \multicolumn{2}{c}{ ELO/M } \\
\cline { 2 - 8 } DSC data & Resin & $+30 \mathrm{wt} \%$ & Resin & $+30 \mathrm{wt} \%$ & Resin & $+30 \mathrm{wt} \%$ & Resin & $+30 \mathrm{wt} \%$ \\
& & Lignin & & Lignin & & Lignin & Rinin \\
\hline$T_{\text {peak }}\left({ }^{\circ} \mathrm{C}\right)$ & 150 & 140 & 153 & 136 & 151 & 137 & 178 & 164 \\
$\left(T_{\text {onset }}-T_{\text {end }}\right)\left({ }^{\circ} \mathrm{C}\right)$ & $(90-250)$ & $(73-250)$ & $(73-250)$ & $(64-225)$ & $(78-250)$ & $(55-220)$ & $(86-250)$ & $(68-250)$ \\
$\Delta H\left(\mathrm{~J} . \mathrm{g}^{-1}\right)$ & 399 & 283 & 334 & 339 & 287 & 301 & 263 & 371 \\
\hline
\end{tabular}


With the addition of $30 \mathrm{wt} \%$ lignin, the $T_{\text {onset }}$ and $T_{\text {peak }}$ decreased for all the studied systems, evidencing that this compound acts not only as filler, but also is involved as coreactant in the crosslinking of the systems. In addition, the conversion of the reaction of the epoxy resins and composites was calculated by integrating the DSC thermograms with linear base approximation, the curve profiles being plotted as a function of the temperature in Figure 3b. Studying the conversion curves of the epoxy resins, it can be seen that the $\mathrm{ELO} / \mathrm{M}$ reaction conversion occurs at higher temperature $\left(110-240{ }^{\circ} \mathrm{C}\right)$, compared to the other three formulations $\left(95-225{ }^{\circ} \mathrm{C}\right)$. The conversion profiles for the blends with lignin were restrained at lower temperature than those of neat resins. The curing reaction of the ELO/M-30\%Lig started relatively slowly and reached a maximum reaction rate at around $165^{\circ} \mathrm{C}$, while for the other three epoxy composites, the maximum reaction rate ranges between $130-140{ }^{\circ} \mathrm{C}$.

Therefore, considering the results obtained from the DSC analyses, it was established that $3 \mathrm{wt} \%$ 1-MIM represents the optimal initiator among those tested. Also, the ratio of $30 \mathrm{wt} \%$ lignin led to an improvement in the reactivity of the systems, demonstrating its contribution as co-reactant to epoxy/anhydride curing.

\section{Thermal and mechanical characterization of thermosets and composites}

The epoxy/anhydride and composites were studied by DMA, the measured storage modulus ( $\left.E^{\prime}\right)$ being displayed in Figure 4. Studying the $E$ ' profile, we can identify the three stages, namely, the glassy plateau, the $\alpha$ transition and the rubbery region. Corroborated with previously reported studies, ${ }^{9,38,39}$ this work also confirms that the nature of the anhydride influences the thermomechanical properties of the developed epoxy polymeric network. The thermoset resins developed by crosslinking ELO with hexahydro-4-methylphthalic anhydride, cis1,2,3,6-tetrahydrophthalic anhydride and methyl nadic anhydride revealed good and similar storage modulus in the glassy plateau $\left(-30{ }^{\circ} \mathrm{C}\right)$, of about 2.1-2.4 GPa, while the system developed with (2-dodecen-1yl)succinic anhydride has a twice lower $E$ ' value $(1.1 \mathrm{GPa})$. Then, with increasing temperature, the $E^{\prime}$ value decreases significantly to a stable value, which indicates that the crosslinked networks are in a stable rubbery state.

The elastic response of the epoxy matrices reinforced with $30 \mathrm{wt} \%$ lignin was also studied. Comparing the DMA analysis data of the ELO/anhydride resins with those of the composites, the addition of lignin decreased the storage modulus of the developed networks, making them less brittle. The storage modulus of the resins in the rubbery region is proportional to the crosslink density $(v)$ of the network, or inversely proportional to the molecular mass between crosslinks $\left(M_{c}\right)$.

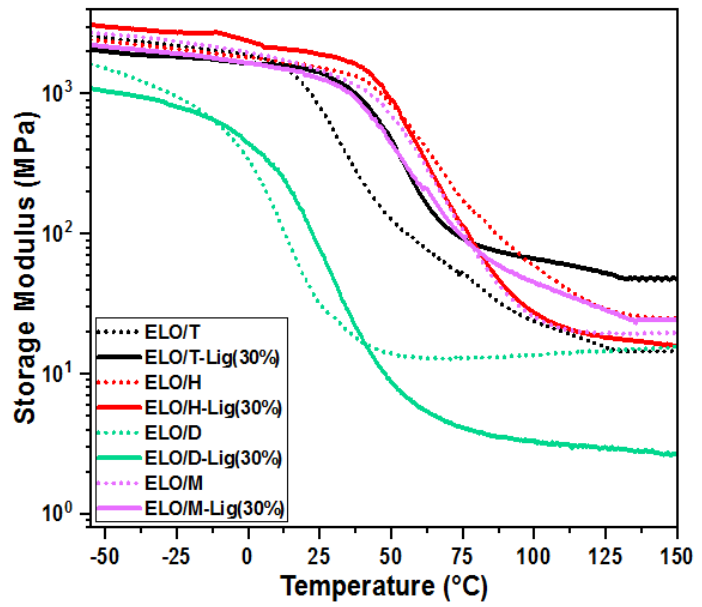

Figure 4: Storage modulus (E') curves of ELO/anhydride resins and composites with $30 \mathrm{wt} \%$ lignin 
Table 2

Physical and thermomechanical properties of ELO/anhydride resins and composites with $30 \mathrm{wt} \%$ lignin

\begin{tabular}{|c|c|c|c|c|c|c|c|c|}
\hline \multirow{2}{*}{ Sample } & \multirow{2}{*}{$\begin{array}{l}\text { Density } \\
\left(\mathrm{g} / \mathrm{cm}^{3}\right)\end{array}$} & \multirow{2}{*}{$\begin{array}{c}\text { Hardness } \\
\text { test } \\
\text { (SD) }\end{array}$} & \multirow{2}{*}{$\begin{array}{c}E \\
\text { in glassy } \\
\text { region }(-30 \\
\left.{ }^{\circ} \mathrm{C}\right)(\mathrm{MPa})\end{array}$} & \multicolumn{2}{|c|}{$\begin{array}{c}\text { Glass } \\
\text { transition }\left({ }^{\circ} \mathrm{C}\right)\end{array}$} & \multirow{2}{*}{$\begin{array}{c}v \\
\left(\mathrm{mmol} \cdot \mathrm{cm}^{-3}\right)\end{array}$} & \multirow{2}{*}{$\begin{array}{c}M \mathrm{c} \\
(\mathrm{g} / \mathrm{mol})\end{array}$} & \multirow{2}{*}{$\begin{array}{c}\text { Gel } \\
\text { content } \\
(\%)\end{array}$} \\
\hline & & & & $\begin{array}{c}T_{\mathrm{g}} \\
\text { (DSC) }\end{array}$ & $\tan \delta$ & & & \\
\hline $\mathrm{ELO} / \mathrm{T}$ & 1.024 & 52 & 2259 & 25 & 41 & 2.04 & 721.02 & 99.45 \\
\hline $\begin{array}{l}\mathrm{ELO} / \mathrm{T}- \\
\mathrm{Lig}(30 \%)\end{array}$ & 0.867 & 65 & 1847 & 49 & 56 & 5.18 & 180.1 & 89.62 \\
\hline ELO/H & 1.062 & 73 & 2139 & 58 & 75 & 2.40 & 392.93 & 97.74 \\
\hline $\begin{array}{l}\mathrm{ELO} / \mathrm{H}- \\
\mathrm{Lig}(30 \%)\end{array}$ & 1.031 & 71 & 2772 & 66 & 72 & 1.60 & 586.03 & 91.76 \\
\hline ELO/D & 1.014 & 36 & 1064 & 12 & 21 & 1.46 & 680.98 & 98.67 \\
\hline $\begin{array}{l}\mathrm{ELO} / \mathrm{D}- \\
\mathrm{Lig}(30 \%)\end{array}$ & 1.035 & 44 & 882 & 18 & 34 & 0.34 & 3615.9 & 89.06 \\
\hline ELO/M & 1.079 & 74 & 2439 & 62 & 75 & 1.87 & 562.02 & 99.81 \\
\hline $\begin{array}{l}\mathrm{ELO} / \mathrm{M}- \\
\mathrm{Lig}(30 \%)\end{array}$ & 0.803 & 65 & 1978 & 46 & 62 & 2.46 & 313.9 & 89.24 \\
\hline
\end{tabular}

Using the DMA data, the crosslink density of the epoxy/anhydride resins and composites was calculated using the equation: ${ }^{40}$

$v=\frac{E^{l}}{3 R T}$

where $E^{\prime}$ represents the storage modulus in the rubbery plateau at $T_{g}+70{ }^{\circ} \mathrm{C}(\mathrm{MPa}), R$ is the universal gas constant, and $T$ is the absolute temperature (K).

The average molecular weight between crosslinks was also calculated based on the relationship established by Tobolsky: ${ }^{41}$

$M c=\frac{3 p R T}{E^{\prime}} \quad M c=\frac{\rho}{\vartheta}$

where $\rho$ is the calculated density $\left(\mathrm{g} . \mathrm{cm}^{-3}\right)$ and $E^{\prime}$ is the storage modulus in the rubbery plateau (MPa) at $130{ }^{\circ} \mathrm{C}$.

The variation of the anhydrides' chemical composition conducts to the development of polymeric networks with various mechanical behavior. The calculated values of $v$ and $M_{c}$ are given in Table 2. Therefore, the increase of the crosslink density reduces chain mobility, making the networks more rigid. Moreover, the crosslink density of the materials is related to the amplitude of $\tan \delta$, so the higher is the peak amplitude, the more elastic is the material. The highest stiffness was obtained for $\mathrm{ELO} / \mathrm{H}$ thermoset, followed by the other resins in the following order: $\mathrm{ELO} / \mathrm{T}>\mathrm{ELO} / \mathrm{M}>\mathrm{ELO} / \mathrm{D}$. The addition of lignin produces a two-fold increase of the crosslink density value in the case of ELO/T and ELO/M systems. In contrast, in the case of $\mathrm{ELO} / \mathrm{H}$ and $\mathrm{ELO} / \mathrm{D}$ thermosets, the $v$ values were reduced two or three times, respectively.

The damping factor $(\tan \delta)$ is related to the cooperative chain motions and is associated with the macroscopic $T_{\mathrm{g}}$ of the thermoset materials. Figure 5 displays the temperature dependence of the loss factor $\tan \delta$ for the analyzed thermosets and composites. The $T_{\mathrm{g}}$ values were determined by DSC and the obtained data are listed in Table 2. A comparison between the $T_{\mathrm{g}}$ values measured by DSC (under no mechanical stress) and the $\tan \delta$ values measured by DMA under mechanical stress at a frequency of $1.0 \mathrm{~Hz}$ (based on the ASTM D7028 international standard $)^{42}$ is presented in Figure 6. The values recorded by the two techniques vary considerably due to the fact that the glass transition is a region between the states of thermodynamic equilibrium, being directly dependent on various physico-chemical and mechanical factors. ${ }^{43,44}$ According to Figure 5, the most elastic epoxy resin is ELO/D, presenting a $\tan \delta$ at $\sim 21{ }^{\circ} \mathrm{C}$. As a function of the anhydride nature, the glass transition increases considerably, reaching $\sim 75{ }^{\circ} \mathrm{C}$ for the systems with hexahydro-4-methylphthalic anhydride or methyl nadic anhydride. The addition of lignin led either to the stiffening of the thermosets or to their plastification. For example, the $\tan \delta$ values of ELO/T and ELO/D composites increased with $\sim 13-15{ }^{\circ} \mathrm{C}$, the lignin increasing the rigidity of materials. For $\mathrm{ELO} / \mathrm{H}$ and $\mathrm{ELO} / \mathrm{M}$ systems, the $\tan \delta$ 
values decreased by around $3{ }^{\circ} \mathrm{C}$ and $13{ }^{\circ} \mathrm{C}$, respectively, the lignin acting here as a plasticizer, thus reducing the fragile character of the epoxy resins. A similar trend was also revealed by the rigidity values (Table 2 ) of the materials obtained by Shore D hardness test. The obtained stiffness values for the thermosets and composites range between $36 \mathrm{SD}$ and $74 \mathrm{SD}$. According to the Shore D scale, these materials belong to medium hard (e.g. door seal, automotive tire tread) to extra hard materials (e.g. solid truck tires, hard wheels). Based on previous studies, ${ }^{10}$ this behavior is related to the structure of the materials and the amount of chemical connections developed in the networks.

The gel content values obtained for the four ELO-based resins and composites are listed in Table 2. We can highlight that all the ELO/anhydride thermosets exhibit a high GC\%, between $97.74 \%$ and $99.81 \%$, indicating that ELO is well cured by the four different anhydrides. Values higher than 99\% indicate that no free species remain in the analyzed network and the crosslinking of these systems is complete. In the case of the epoxy resins reinforced with $30 \mathrm{wt} \%$ lignin, a slight decrease in gel content values can be observed, varying between $89 \%$ and $91.76 \%$. These lower values of the GC\% for composites can be caused by the unlinked lignin present in the materials composition. With the immersion into acetone of the

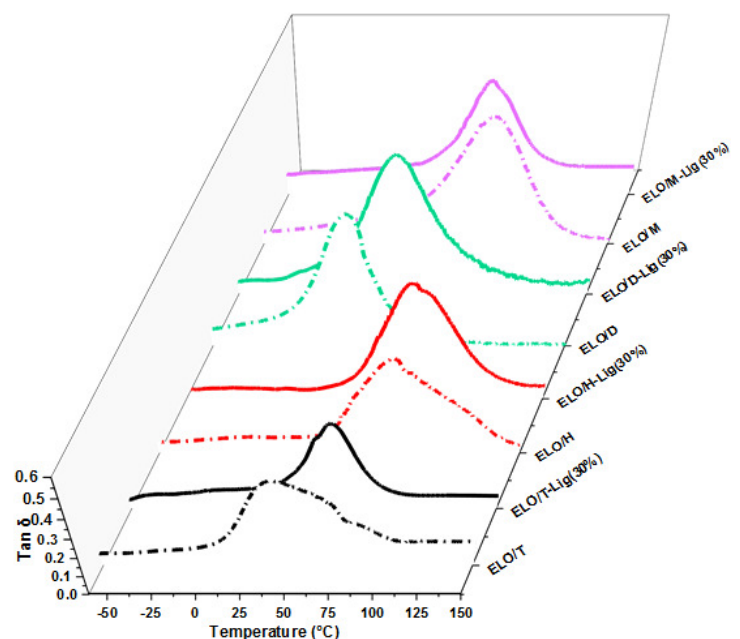

Figure 5: Temperature dependence of loss factor $\tan \delta$ for the ELO/anhydride thermosets and composites composites, the chemically unbound lignin particles were dislocated from the material's structure, being released into the solvent, thus leading to the formation of free spaces in the polymeric network.

\section{Thermal stability studies}

Figure 7 presents the TGA analysis under oxidative atmosphere of the ELO/anhydride polymeric resins and their composites with 30 wt $\%$ Lig. The degradation temperature $\left(T_{5 \%}\right)$ of the materials and the temperature corresponding to the maximum decomposition rate $\left(T_{\mathrm{dmax}}\right)$ were recorded from the TGA/DTG data and listed in Table 3, together with the statistic heat-resistance index $\left(T_{\mathrm{s}}\right)$. The $T_{\mathrm{s}}$ factor represents the temperature of the polymers in the physical heat tolerance limit and was calculated using the equation: ${ }^{37,45-47}$ $\mathbf{T}_{5}=0.49\left[T_{5 \%}+0.6\left(T_{30 \%}-T_{5 \%}\right)\right]$

where the $T_{30 \%}$ is the temperature at which the analyzed materials lose $30 \%$ of their mass.

The obtained data show that the cured epoxy/anhydride resins are generally thermally stable up to $300{ }^{\circ} \mathrm{C}$, excepting the system with methyl nadic anhydride, which presents a $T_{5 \%}$ at $\sim 284{ }^{\circ} \mathrm{C}$. This minor difference in thermal stability between the systems demonstrates that the anhydride nature does not significantly influence the thermal behavior of the polymeric materials, which was also highlighted by Gerbase et al. ${ }^{38}$

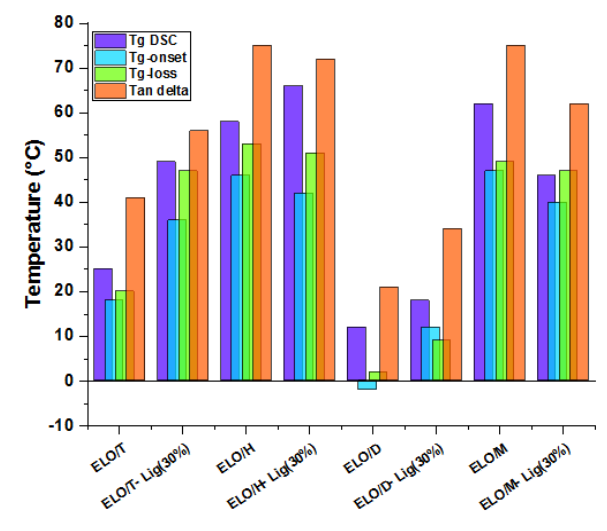

Figure 6: Glass transition temperatures for the epoxy thermoset resins and composites determined by DSC and DMA 


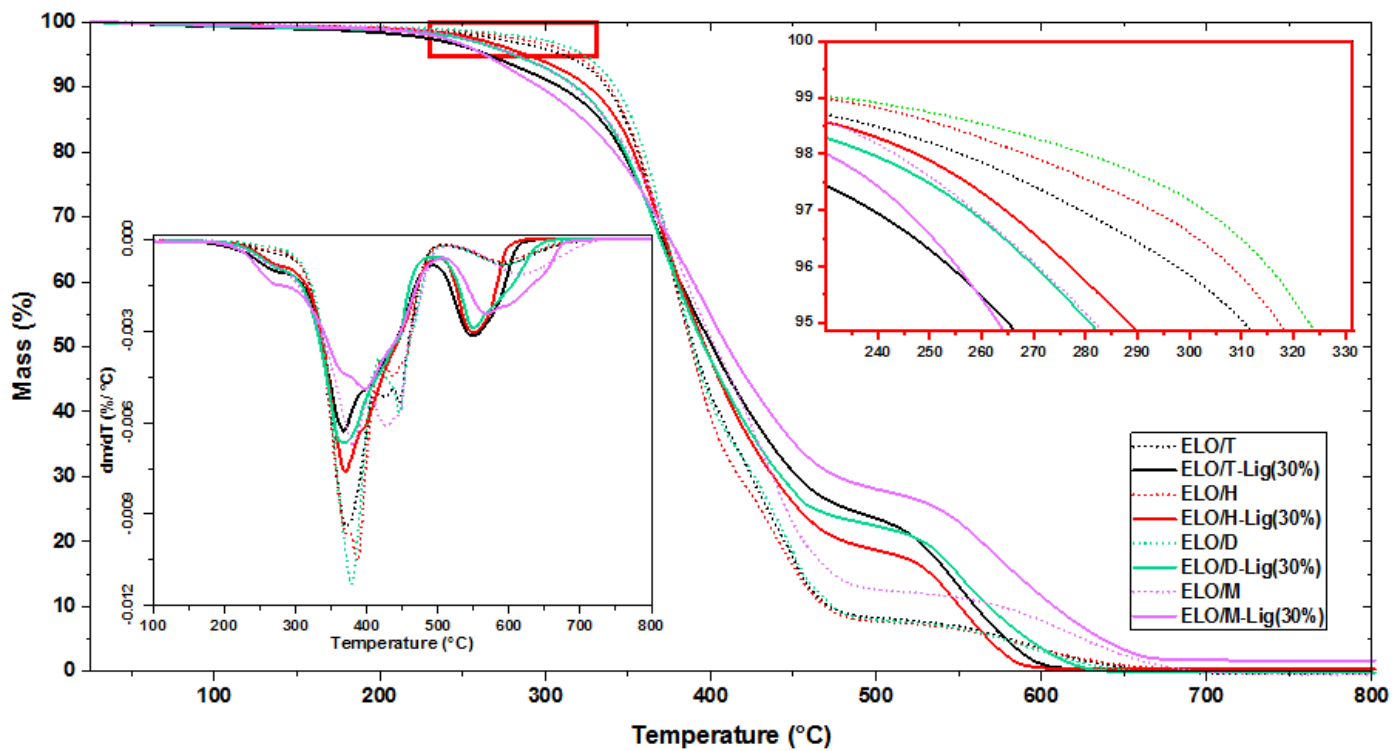

Figure 7: TGA and DTG (bottom left corner) curves as a function of temperature for resins and composites, heating at $10{ }^{\circ} \mathrm{C} / \mathrm{min}$, under air flow

Table 3

TGA/DTG results for resins and composites analysis

\begin{tabular}{lccc}
\hline Sample & $T_{5 \%}\left({ }^{\circ} \mathrm{C}\right)$ & $T_{\mathrm{dmax}}\left({ }^{\circ} \mathrm{C}\right)$ & $T_{\mathrm{s}}\left({ }^{\circ} \mathrm{C}\right)$ \\
\hline ELO/T & 310 & 370 & 170 \\
ELO/T-Lig(30\%) & 270 & 370 & 160 \\
ELO/H & 320 & 389 & 171 \\
ELO/H-Lig(30\%) & 290 & 370 & 165 \\
ELO/D & 320 & 380 & 172 \\
ELO/D-Lig(30\%) & 282 & 369 & 163 \\
ELO/M & 284 & 379 & 164 \\
ELO/M-Lig(30\%) & 264 & 399 & 161 \\
\hline
\end{tabular}

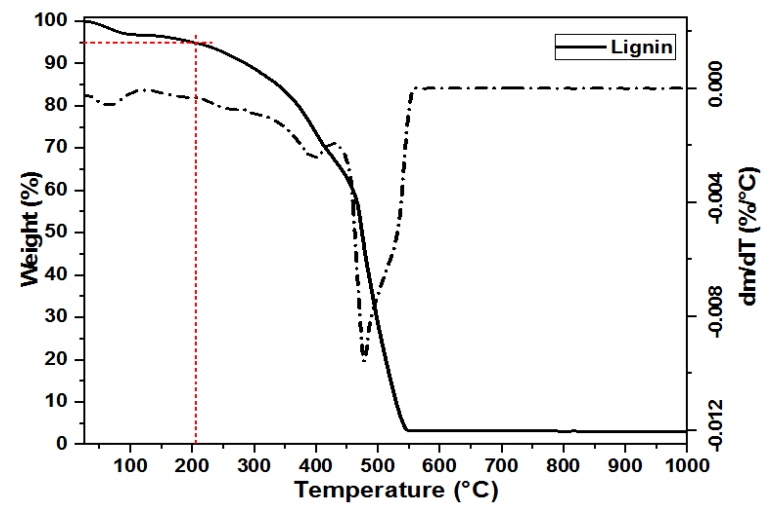

Figure 8: TGA/DTG curve versus temperature for the raw Kraft lignin

The addition of lignin led to a slight diminution in the thermal stability of the composites, still remaining very good, above $265{ }^{\circ} \mathrm{C}$. This result may be due to the thermal stability of the raw lignin $\left(T_{5 \%}=202{ }^{\circ} \mathrm{C}\right.$ ) (Fig. 8).
Studying the DTG curves, we can observe the presence of two complex and major inflection points for all the epoxy resins and composites. Before the first major degradation step, a slight decomposition shoulder between 200-280 ${ }^{\circ} \mathrm{C}$ can be observed for all the 
developed materials. This first small step can be attributed to the volatilization of the adsorbed water, which in the case of the composites overlaps with the beginning of the thermal decomposition of lignin. ${ }^{4-50}$ The first step represents the main thermal degradation stage for both the resins and the composites. This decomposition stage appears as a large and complex exothermic peak ranging between $300{ }^{\circ} \mathrm{C}$ and up to $510{ }^{\circ} \mathrm{C}$, with a maximum at about $370-400{ }^{\circ} \mathrm{C}\left(T_{\mathrm{dmax}}\right.$, Table 3 ), and is associated with the thermolysis of the polymer structure. In the case of the epoxy resins, the mass loss in this step is about 80$89 \%$, this percentage varying depending on the anhydride nature in the order: ELO/M < $\mathrm{ELO} / \mathrm{D}<\mathrm{ELO} / \mathrm{T}<\mathrm{ELO} / \mathrm{H}$. Likewise, it was observed that, although the addition of lignin reduced the $T_{5 \%}$ values of the composites, their mass loss percentage in the first main step decreased considerably, compared to the neat resins, being about $58-73 \%$. The second degradation stage, of thermo-oxidative degradation and carbonization of the resins and composites, appears in the DTG thermograms (Fig. 7) as a well-defined exothermic peak ranging between $500-750{ }^{\circ} \mathrm{C}$. At this stage, the mass loss of the epoxy resins is about $7-13 \%$, while for the related composites filled with $30 \mathrm{wt} \%$ lignin, the mass loss percentage ranges from 18 up to $26 \%$.

\section{Water absorption}

The water absorption of the prepared materials was evaluated using two different techniques: by the ASTM D570 method and by the DSC method. The water uptake evolution of the epoxy resins and composites after $24 \mathrm{~h}$ of immersion is displayed in Figure 9. The water absorption of materials is influenced by various factors, as for example, the existence of microcracks and pores, which are present in some epoxy resins. ${ }^{51-54}$ Another factor that influences the water absorption is the presence of free hydroxyl or other polar groups, which can increase the WA by hydrogen bonding. ${ }^{55}$ The water gain in the neat epoxy polymers, after $24 \mathrm{~h}$ of immersion, ranged between $0.6 \%$ and $1.2 \%$, depending on the anhydride nature. Studying the obtained WA results and comparing them with the calculated crosslink density (Table 2), it can be observed that the lower is the crosslink density, the higher is the WA. So, the moisture uptake values of the epoxy/anhydride resins are in the following order: $\mathrm{ELO} / \mathrm{D}>\mathrm{ELO} / \mathrm{M}>\mathrm{ELO} / \mathrm{T}>\mathrm{ELO} / \mathrm{H}$.

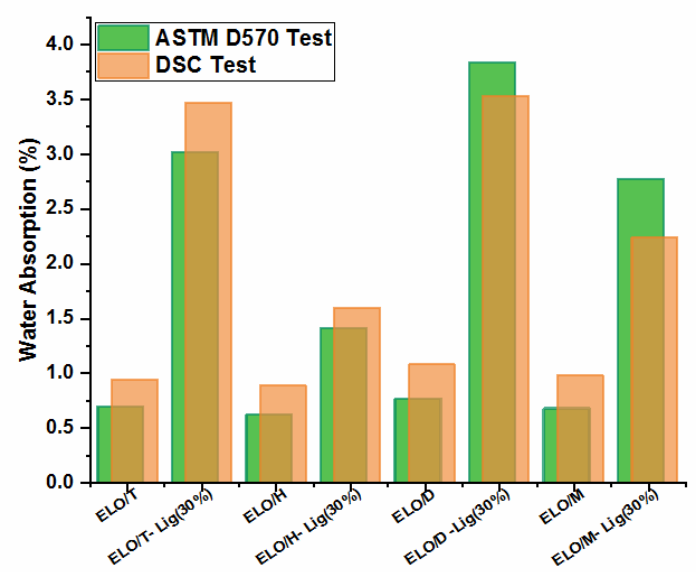

Figure 9: WA\% after $24 \mathrm{~h}$ of immersion: comparison between ASTM D570 standard test and DSC test

The addition of $30 \mathrm{wt} \%$ lignin increased 24-fold the WA values of the composites. Lignocellulose fibers are highly hydrophilic due to the presence of $-\mathrm{OH}$ groups, permitting moisture absorption by hydrogen bonding. ${ }^{53}$
From Figure 9, we can notice that even if the amount of WA increases with the addition of lignin, it still remains relatively low, between $1.4-3.7 \%$. We have already shown that the presence of filler in the composites interferes 
with the curing process of the matrix, leading to a decrease in the crosslinking of the matrix, which facilitates the penetration of water into the polymer network. The decrease of composites' WA can be achieved using adequate coatings or fiber treatment. ${ }^{56}$

\section{CONCLUSION}

Epoxidized linseed oil was copolymerized with various anhydrides, such as cis-1,2,3,6tetrahydrophthalic anhydride, hexahydro-4methylphthalic anhydride, (2-dodecen-1yl)succinic anhydride and methyl nadic anhydride, the reactions being initiated by 1methylimidazole. Afterwards, the designed epoxy/anhydride resins were reinforced with a very high amount (30 wt $\%$ ) of a natural derived raw material, namely lignin. The reactivity of the resins and the influence of the filler on the curing process were investigated by the DSC technique. DSC analyses showed that the copolymerization reaction was improved in the presence of lignin, by decreasing the reaction temperature interval and $T_{\text {peak }}$.

The variation of the anhydride chemical nature led to the development of materials with modular properties. The $\tan \delta$ values of the ELO-based resins ranged between $21{ }^{\circ} \mathrm{C}$ and $75{ }^{\circ} \mathrm{C}$, the materials varying from elastic to rigid. The addition of lignin modified differently the mechanical properties of the composites, depending on the nature of the polymer matrix; for the systems ELO/T and ELO/D, the lignin acted as a filler, imparting rigidity to the materials, while for the systems $\mathrm{ELO} / \mathrm{H}$ and $\mathrm{ELO} / \mathrm{M}$, the lignin acted as a plasticizer, reducing the brittle character of the resins and making the materials more ductile.

Based on the Shore D hardness test, the obtained resins and composites are classified into the medium hard to extra hard material category, with values from $36 \mathrm{SD}$ up to $74 \mathrm{SD}$. Moreover, the synthesized polymeric materials revealed very low water absorption, with values between $0.6-1.2 \%$ for the resins and $1.4-3.7 \%$ for the composites with lignin. These materials also showed high gel content, being over $98 \%$ for the resins and $\sim 89-92 \%$ for the composites.

In conclusion, in this work, various polymeric materials were synthesized with good physico-chemical, thermal and thermomechanical properties. The lignin that was used in very large quantities played the role of both a co-macromonomer and a filler, thus leading to the development of new polymer networks. These thermosets with high biobased content have the potential to substitute some petroleum-based polymers in applications such as automotive parts, composites, semi-manufactured products, etc.

ACKNOWLEDGMENT: This work was supported by ECOXY project. ECOXY is a project funded by the European Commission. This project has received funding from the Bio Based Industries Joint Undertaking under the European Union's Horizon 2020 research and innovation program (Grant agreement $n^{\circ}$ 744311).

\section{REFERENCES}

1 D. Hosler, Science, 284, 1988 (1999), https://doi.org/10.1126/science.284.5422.1988

2 A. Okunola, I. O. Kehinde, A. Oluwaseun and E. A. Olufiropo, J. Toxicol. Risk Assess., 5, 021 (2019), 4061.1510021

3 B. Kamm, P. R. Gruber and M. Kamm, "Biorefineries-Industrial Processes and Products. Status Quo and Future Directions", Wiley-VCH Verlag GmbH \& Co. KGaA, Weinheim, 2006, vol. 1, https://doi.org/10.1002/9783527619849.ch22

4 G. Mashouf Roudsari, A. K. Mohanty and M. Misra, ACS Sustain. Chem. Eng., 5, 9528 (2017), https://doi.org/10.1021/acssuschemeng.7b01422

5 E. Ramon, C. Sguazzo and P. Moreira, Aerospace, $\quad 5, \quad 110 \quad$ (2018), https://doi.org/10.3390/aerospace5040110

6 J.-P. Pascault and R. J. Williams, "Epoxy Polymers-New Materials and Innovations", WileyVCH Verlag GmbH \& Co. KGaA, 2010

7 Y. Xia and R. C. Larock, Green Chem., 12, 1893 (2010), https://doi.org/10.1039/c0gc00264j

8 N. B. Samarth and P. A. Mahanwar, Open J. Org. Polym. Mater., 05, 1 (2015), https://doi.org/10.4236/ojopm.2015.51001

9 N. Boquillon and C. Fringant, Polymer (Guildf), 41, $8603 \quad$ (2000), https://doi.org/10.1016/S0032-3861(00)00256-1

10 M. D. Samper, V. Fombuena, T. Boronat, D. García-Sanoguera and R. Balart, J. Am. Oil Chem. Soc., $\quad 89, \quad 1521 \quad$ (2012), https://doi.org/10.1007/s11746-012-2041-y

11 C. Di Mauro, A. Genua and A. Mija, Mater. Adv., $\quad 1, \quad 1788$ (2020), https://doi.org/10.1039/D0MA00370K

12 C. Di Mauro, T.-N. Tran, A. Graillot and A. Mija, ACS Sustain. Chem. Eng., 8, 7690 (2020), https://doi.org/10.1021/acssuschemeng.0c01419 
13 C. Di Mauro, S. Malburet, A. Genua, A. Graillot and A. Mija, Biomacromolecules, 21, 3923 (2020), https://doi.org/10.1021/acs.biomac.0c01059

14 D. J. Morris and I. Ahmed, "The Carbohydrate Economy: Making Chemicals and Industrial Materials from Plant Matter", Institute for Local Self-Reliance, 1992

15 R. Wool and X. S. Sun, "Bio-Based Polymers and Composites", $1^{\text {st }}$ ed., Elsevier, 2005

16 S. N. Khot, J. J. Lascala, E. Can, S. S. Morye, G. I. Williams et al., J. Appl. Polym. Sci., 82, 703 (2001), https://doi.org/10.1002/app.1897

17 I. Delidovich, P. J. C. Hausoul, L. Deng, R. Pfützenreuter, M. Rose et al., Chem. Rev., 116 , 1540

https://doi.org/10.1021/acs.chemrev.5b00354

18 A. Barakat, H. de Vries and X. Rouau, Bioresour. Technol., 134, 362 (2013), https://doi.org/10.1016/j.biortech.2013.01.169

19 M. Taherzadeh and K. Karimi, Int. J. Mol. Sci., 9, 1621

(2008), https://doi.org/10.3390/ijms9091621

20 V. K. Ponnusamy, D. D. Nguyen, J. Dharmaraja, S. Shobana, J. R. Banu et al., Bioresour. Technol., 271, 462 (2019), https://doi.org/10.1016/j.biortech.2018.09.070

${ }_{21}$ A. Ház, M. Jablonský, I. Šurina, F. Kačík, T. Bubeníková et al., Forests, 10, 483 (2019), https://doi.org/10.3390/f10060483

22 J. H. Lora and W. G. Glasser, J. Polym. Environ., $\quad \mathbf{1 0}, \quad 39 \quad$ (2002), https://doi.org/10.1023/A:1021070006895

23 O. A. T. Dias, D. R. Negrão, R. C. Silva, C. S. Funari, I. Cesarino et al., Mol. Cryst. Liq. Cryst., 628, 72

(2016), https://doi.org/10.1080/15421406.2015.1137677

24 O. A. T. Dias, M. Sain, I. Cesarino and A. L. Leão, Polym. Adv. Technol., 30, 70 (2019), https://doi.org/10.1002/pat.4444

25 M. A. S. Anwer, H. E. Naguib, A. Celzard and V. Fierro, Compos. Part B Eng., 82, 92 (2015), https://doi.org/10.1016/j.compositesb.2015.08.028 26 O. Gordobil, R. Delucis, I. Egüés and J. Labidi, Ind. Crop. Prod., 72, 46 (2015), https://doi.org/10.1016/j.indcrop.2015.01.055

27 Q. Ping, J. Xiao and J. Zhao, Adv. Mater. Res., 1195 (2011)

https://doi.org/10.4028/www.scientific.net/AMR.2 36-238.1195

28 J. Sun, C. Wang, J. C. C. Yeo, D. Yuan, H. Li et al., Macromol. Mater. Eng., 301, 328 (2016), https://doi.org/10.1002/mame.201500310

29 Q. Yin, W. Yang, C. Sun and M. Di, BioResources, 7, $5737 \quad$ (2012), https://doi.org/10.15376/biores.7.4.5737-5748

30 M. Fache, B. Boutevin and S. Caillol, Green Chem., 18, 712 (2016), https://doi.org/10.1039/c5gc01070e
31 F. Ferdosian, Z. Yuan, M. Anderson and C. Xu, Thermochim. Acta, 618, 48 (2015), https://doi.org/10.1016/j.tca.2015.09.012

32 R. Dinu, C. Cantarutti and A. Mija, ACS Sustain. Chem. Eng., 8, $6844 \quad$ (2020), https://doi.org/10.1021/acssuschemeng.0c01759

33 R. Dinu and A. Mija, J. Mater. Sci. Res., 9, 183 (2020)

34 ASTM-D570, Water Absorption of Plastics, 1998, https://doi.org/10.1520/D0570-98

35 S. G. Tan, Z. Ahmad and W. S. Chow, Polym. Int., $\quad 63, \quad 273 \quad$ (2014), https://doi.org/10.1002/pi.4501

36 X. Liu, W. Xin and J. Zhang, Green Chem., 11, 1018 (2009), https://doi.org/10.1039/b903955d

37 S. Ma, X. Liu, L. Fan, Y. Jiang, L. Cao et al., ChemSusChem, 7, $555 \quad$ (2014), https://doi.org/10.1002/cssc.201300749

38 A. E. Gerbase, C. L. Petzhold and A. P. O. Costa, J. Am. Oil Chem. Soc., 79, 797 (2002), https://doi.org/10.1007/s1 1746-002-0561-z

39 H. Miyagawa, A. K. Mohanty, M. Misra and L. T. Drzal, Macromol. Mater. Eng., 289, 629 (2004), https://doi.org/10.1002/mame.200400004

40 P. J. Flory, "Principles of Polymer Chemistry", Cornell University Press, 1953

41 A. V. Tobolsky, "Properties and Structure of Polymers", Wiley, New York, 1960

42 ASTM-D7028, Standard Test Method for Glass Transition Temperature (DMA Tg) of Polymer Matrix Composites by Dynamic Mechanical Analysis (DMA), 2008, https://doi.org/10.1520/D7028-07E01.2

43 M. Fache, A. Viola, R. Auvergne, B. Boutevin and S. Caillol, Eur. Polym. J., 68, 526 (2015), https://doi.org/10.1016/j.eurpolymj.2015.03.048

44 I. M. Kalogeras and H. E. Hagg Lobland, J. Mater. Educ., 34, 69 (2012)

${ }^{45}$ C. Aouf, H. Nouailhas, M. Fache, S. Caillol, B. Boutevin et al., Eur. Polym. J., 49, 1185 (2013), https://doi.org/10.1016/j.eurpolymj.2012.11.025

46 H. Nouailhas, C. Aouf, C. Le Guerneve, S. Caillol, B. Boutevin et al., J. Polym. Sci. Part A Polym. Chem., 49, $2261 \quad$ (2011), https://doi.org/10.1002/pola.24659

47 S. Ma, C. S. Kovash and D. C. Webster, J. Coatings Technol. Res., 14, 367 (2017), https://doi.org/10.1007/s1 1998-016-9863-8

48 S. Hirose, T. Hatakeyama and H. Hatakeyama,

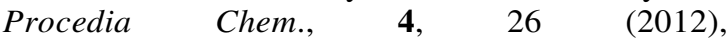
https://doi.org/10.1016/j.proche.2012.06.004 49 T. Väisänen, O. Das and L. Tomppo, J. Clean. Prod., 149, 582 (2017), https://doi.org/10.1016/j.jclepro.2017.02.132

50 P. Liminana, D. Garcia-Sanoguera, L. QuilesCarrillo, R. Balart and N. Montanes, Compos. Part B Eng., 144, 153 (2018), https://doi.org/10.1016/j.compositesb.2018.02.031 
51 A. Moudood, A. Rahman, A. Öchsner, M. Islam and G. Francucci, J. Reinf. Plast. Compos., 38, 323

https://doi.org/10.1177/0731684418818893

52 M. Assarar, D. Scida, A. El Mahi, C. Poilâne and R. Ayad, Mater. Des., 32, 788 (2011), https://doi.org/10.1016/j.matdes.2010.07.024

53 A. Moudood, A. Rahman, H. M. Khanlou, W. Hall, A. Öchsner et al., Compos. Part B Eng., 171, 284

(2019)

https://doi.org/10.1016/j.compositesb.2019.05.032
54 E. Muñoz and J. A. García-Manrique, Int. J. Polym. Sci., 2015, 1 (2015), https://doi.org/10.1155/2015/390275

55 G. Capiel, J. Uicich, D. Fasce and P. E Montemartini, Polym. Degrad. Stabil., 153, 165 (2018),

https://doi.org/10.1016/j.polymdegradstab.2018.04 .030

56 F. Ahmad, H. S. Choi and M. K. Park, Macromol. Mater. Eng., 300, 10 (2015), https://doi.org/10.1002/mame.201400089 